\title{
La Cuba poscomunista... ¿un parque temático? Imaginarios utópicos y contrautópicos en La Habana literaria
}

\author{
Alejandro Del Vecchio \\ Universidad Nacional de Mar del Plata \\ (UNdMP, Argentina)
}

\section{Resumen}

La crisis económica y el progresivo derrumbe del ideal del Hombre Nuevo provoca durante los '9o, en Cuba, la emergencia de una nueva tendencia narrativa (denominada "poscomunista», "postsoviética» o "posrevolucionaria» y con representantes como Antonio José Ponte y Pedro Juan Gutiérrez), donde la lógica del intercambio artístico abandona la tutela del gobierno revolucionario para instalarse en una lógica comercial caracterizada por la concepción del propio cuerpo como mercancía o valor de cambio, por el exhibicionismo exacerbado de las voces narradoras y por la consecuente consideración del lector como voyeur. Frente a la utopía carpenteriana, las imágenes literarias de Centro Habana y La Habana vieja en ruinas, las figuras de Castro y Guevara adornando objetos de consumo masivo, y la exótica oferta sexual de la isla afirman un imaginario posutópico usufructuado turísticamente, como si Cuba fuera un parque temático,

Palabras clave:

imaginarios utópicos, literatura cubana, Alejo Carpentier, Pedro Juan Gutiérrez, Antonio José Ponte 
una reserva natural o un museo a cielo abierto. Cabe preguntarse entonces de qué modo La Habana textual, La Habana hecha de palabras (reinvención, a su vez, de la ciudad geográfica que está fuera de los textos), se constituye en centro generador de un imaginario social donde la utopía dominante del siglo XX resulta irreversiblemente penetrada por la sociedad de consumo.

\section{Abstract}

\section{Post-communist Cuba... a Theme Park? Utopian and Counter-Utopian Imaginaries in Literary Havana}

The economic crisis and the progressive collapse of the Che Guevara's "New Man» generated during the '9o, in Cuba, the emergence of a new narrative trend (named "postcommunist», "postsoviet» or "postrevolutionary" and with representatives like Antonio José Ponte and Pedro Juan Gutiérrez), where the logic of the artistic exchange left the guardianship of the revolutionary government to establish itself in a commercial logic. This logic is characterized by the conception of the body itself as merchandise or value of change, by the exacerbated exhibitionism of the narrative voices and by the consequent account of the reader as a voyeur. Opposite to Alejo Carpentier's Utopia, the literary images of Center Havana and Old Havana in ruins, the figures of Castro and Guevara decorating objects of massive consumption, and the exotic sexual offer of the island, affirm a post Utopian imaginary exploited by tourism, as if Cuba were a theme park, a natural reserve or an open sky museum. It is worth asking then how the textual Havana, the Havana made of words (a reinvention of the geographical city that is outside the texts), is a generator of a social imaginary where the dominant utopia of the twentieth century is irreversibly permeated by the consumer society.
Keywords:

utopian imaginaries, cuban literature, Alejo Carpentier, Pedro Juan Gutiérrez, Antonio José Ponte 


\section{Resumo}

\section{A Cuba pós-comunista... um parque temático? Imaginários utópicos e contra utópicos em \\ Havana literária}

A crise econômica e o colapso progressivo do ideal do Novo Homem provocam, durante os anos 90, em Cuba, o surgimento de uma nova tendência narrativa (chamada "pós-comunista», "pós-soviética» ou "pósrevolucionária» e com representantes como Antonio José Ponte e Pedro Juan Gutiérrez), onde a lógica do intercâmbio artístico abandona a tutela do governo revolucionário para instalar-se numa lógica comercial. Lógica caracterizada pela concepçáo do próprio corpo como mercadoria ou valor de troca, pelo exibicionismo exacerbado das vozes narrativas e pela consequente explicação do leitor como voyeur. Perante a utopia carpenteriana, as imagens literárias do Centro Havana e A Havana Velha em ruínas, as figuras de Castro e Guevara ornamentando objetos de consumo de massas, e a exótica oferta sexual da ilha afirmam um imaginário pós-utópico usufrutuado para turismo, como se Cuba fosse um parque temático, uma reserva natural ou um museu ao ar livre. Vale a pena perguntar entấo como Havana textual, Havana fez das palavras (reinvenção, por sua vez, da cidade geográfica que está fora dos textos), é um gerador de um imaginário social onde a utopia dominante do século XX é irreversivelmente permeada pela sociedade de consumo..
Palavras-chave:

imaginários utópicos, literatura cubana, Alejo Carpentier, Pedro Juan Gutiérrez, Antonio José Ponte 
En julio de 2006, el expresidente del gobierno de España, José María Aznar, afirmó en un video enviado a la Fundación Nacional Cubano Americana (FNCA) (la más influyente del exilio cubano en Miami) que un sector de la izquierda había transformado a Cuba en un "parque temático de la prehistoria dogmática». Más allá de la boutade de Aznar (poco sorpresiva si consideramos su posicionamiento ideológico), la idea de que la Cuba revolucionaria se transformó progresivamente en una escenografía vaciada de sentido ideológico aparece de manera recurrente en gran parte de la literatura producida dentro y fuera de la isla desde el Período Especial hasta nuestros días. Me refiero a textos donde las imágenes de Centro Habana y La Habana vieja en ruinas, las efigies de Castro y Guevara adornando objetos de consumo masivo, y la abundante y exótica oferta sexual de la isla afirman un imaginario posutópico usufructuado turísticamente como si se tratara de un parque de atracciones, una reserva natural o un museo a cielo abierto.

En un ensayo tan breve como polémico, ${ }^{1}$ Duanel Díaz Infante sostiene que lo espectacular es constitutivo de la Revolución. La voluntad de eternizar ese momento épico de extrañamiento y fascinación que fue la entrada en 1959 de los rebeldes barbudos en La Habana -en tanto la permanente ostentación de la barba y el traje de campaña verde olivo se convierten (a fuerza de fijación visual) en símbolos de poder - transforma la Revolución en un espectáculo que se pone en escena a sí mismo una y otra vez. «Se diría que mientras el Estado intentaba trascender por todos los medios el mercado, de hecho se producía un único producto para consumo interno y externo: la Revolución", sostiene Díaz Infante (2012). Desde esta línea de lectura, que con el paso de los años la famosa imagen del Che Guevara tomada por Alberto Díaz (Korda) deviniera en principal ícono pop del siglo XX para adornar tazas, remeras, encendedores y gorras (entre otros muchos elementos) no constituiría una traición o tergiversación de su esencia revolucionaria, sino por el contrario, su consumación definitiva. Al postularse como la fotografía más reproducida y comercializada del mundo, no solo su aura (en términos de Benjamin) $)^{2}$ se atrofia, sino que además la imagen pierde su carga de significado ideológico para convertirse en un objeto feti-ché (haciendo un previsible juego de palabras). La paradoja resulta evidente. Por un lado, el mercado se apropia de la figura emblemática de un proceso revolucionario que intentó combatirlo. Por otro, la reproducción masiva de estos 
objetos responde a un sistema de control y dominio de las masas que absorbe y revierte el sentido de rebeldía de que era portador Guevara: precisamente el pasaje de las masas populares desde sujetos hacia objetos de la acción política se explicaría, para Díaz Infante, por la condición espectacular del guevarismo.

Pero incluso antes de que la industria cultural pusiera a circular imágenes del Che al lado de, por ejemplo, las de Marilyn Monroe (como si se tratara de figuras con significados y pesos equivalentes), las puestas en escena de Guevara ya apuntaban a fijar un imaginario rebelde sustentado en base a la figuración de los jóvenes en el poder, es decir, en base a la formación del Hombre Nuevo socialista. Lo espectacular ya estaba allí. Los testimonios de intelectuales que visitaron al Che en la sede del Banco Nacional habanero son elocuentes al respecto. Neruda, por recordar un caso emblemático, citado por el guerrillero insólitamente a la medianoche (igual que Sartre), anota en sus memorias: «El Che llevaba botas, uniforme de campaña y pistolas a la cintura. Su indumentaria desentonaba con el ambiente bancario de la oficina» (Díaz Infante, 20I2). Se trataba, para Duanel Díaz, de un golpe de efecto donde la nocturnidad aumentaba el extrańamiento de aquel cuadro fundacional de la mitología revolucionaria. Frente a los intelectuales, Guevara se autofiguraba como la Revolución.
Historiar los avatares del ideal del Hombre Nuevo a lo largo del proceso revolucionario sería una tarea ardua y ajena al propósito de este trabajo; no obstante, resulta innegable la influencia que ejerció sobre la sociedad cubana (e incluso más allá de las fronteras) hasta su caída acaso definitiva. Como demuestra Carmelo Mesa-Lago, el modelo socialista cubano puede pensarse en forma de ciclos recurrentes de diverso grado y extensión que, de modo alternativo, han alejado o acercado la política económica y social al mercado, aunque con efectos opuestos. Entre la inestabilidad y la incertidumbre (la mayoría de estos ciclos no duró mucho más de cinco años), esta alternancia conspiró contra el éxito de cada medida económica pensada a largo plazo, debido al escaso tiempo otorgado a su implementación. Con el objetivo de simplificar, Mesa-Lago llama «idealistas» a los ciclos marcados por ideas centralistas y contrarias al mercado, y "pragmáticos» a los orientados hacia el mercado y una apertura económica mayor. En palabras de Mesa-Lago:

En los ciclos idealistas la dirigencia política fijó metas muy ambiciosas, por ejemplo: lograr en cuatro años la producción industrial por habitante mayor en América Latina, fabricar io millones de toneladas de azúcar y luego doblar dicha producción, forjar un «Hombre Nuevo» solidario y altruista, y alcanzar la autosuficiencia alimentaria en un 
quinquenio. Todos estos planes fracasaron y provocaron efectos económico-sociales adversos así como crisis. Ello, a su vez, generó una amenaza (real o percibida) de inestabilidad político-social, por lo cual la dirigencia cambió la política idealista con un sesgo hacia el mercado, a fin de salvar o reforzar el régimen y mantener su poder. Los ciclos pragmáticos han producido mejoras moderadas en la economía y en los niveles de vida, pero también han causado algunos efectos sociales negativos, como desempleo declarado (abierto o visible) y desigualdad. Cada vez que la dirigencia juzgó que el régimen se había fortalecido lo suficiente bajo un ciclo pragmático, lanzó un nuevo ciclo idealista y así en un círculo vicioso. (2OI2:20)

Más allá de las medidas económicas, como destaca Mesa-Lago, el gobierno revolucionario intentó durante los períodos idealistas recuperar la figura de Ernesto Guevara y especialmente, resucitar al devaluado Hombre Nuevo. Sin embargo, el continuo debilitamiento de la frágil economía en recesión de la isla y el evidente retroceso de las masas populares frente a la conformación de una elite gobernante en la representación tanto del Partido como de su Comité Central (es decir, en el liderazgo del país) provoca una reacción inversa al exagerado optimismo oficial. Así, los jóvenes cubanos, destinados a encarnar al hombre socialista del futuro (ese Hombre Nuevo invulnerable ante los estímulos materiales y portador incorruptible de la moral revolucionaria) caerían en el sopor de la desilusión y el desencanto.

Este progresivo derrumbe de un sistema ideológico que privilegiaba lo colectivo frente a lo individual provoca durante los '9o la emergencia de una nueva tendencia narrativa (con frecuencia denominada "poscomunista», "postsoviética» o "posrevolucionaria» y que tiene a Antonio José Ponte y Pedro Juan Gutiérrez como dos exponentes estelares), articulada en la interacción simultánea de vectores como literatura/vida, exhibicionismo/voyeurismo y cuerpo/mercado. Durante el «Período Especial en Tiempos de Paz», aquella conciencia comunista incompatible con el mercado y el dinero, y sujetos colectivos como "pueblo» $\mathrm{o}$ incluso "Revolución» resultan impugnados frente a la crisis. El retorno del sujeto individualista y de las retóricas de la intimidad, hechos asociados a la caída de los grandes metarrelatos de occidente, puede entonces indagarse para el caso cubano como correlato de, entre otros factores, la referida agonía del Hombre Nuevo y el trabajo voluntario. En este contexto, la lógica del intercambio artístico abandona la tutela del gobierno revolucionario para instalarse en una lógica comercial: concepción del propio cuerpo como mercancía o valor de cambio, exhibicionismo de las voces narradoras y correlativa consideración del lector como 
voyeur (cercano conceptualmente, según Esther Whitfield, a la figura del turista). De allí que edificios en ruinas y también vidas $a$-rruinadas (porque en estos textos el cuerpo humano se homologa al cuerpo urbanístico y social devastado del país) aparezcan como objetos de la fascinación del turista-lector extranjero.

\section{De la ciudad de las columnas al arte nuevo de hacer ruinas}

Desde la llegada de Colón, América había sido vista y pensada desde parámetros europeos como paraíso terrenal y utopía. Este "Nuevo Mundo» constituía la oportunidad para fundar una sociedad asentada sobre una tierra virgen bendecida por la abundancia ${ }^{3}$ y aislada de toda corrupción, donde instaurar los ideales de una comunidad más justa y próspera. América era el espacio donde residía la Fuente de la Eterna Juventud, donde se ocultaban El Dorado o la Ciudad Encantada de los Césares. En este sentido, Bronislaw Baczko muestra cómo una vez instalado como régimen del imaginario social, el paradigma utópico adquiere inercia y dinamismo. Los relatos del descubrimiento se imitan y multiplican: «La utopía mantiene, entonces, múltiples y complejas relaciones con las ideas filosóficas, las letras, los movimientos sociales, las corrientes ideológicas, el simbolismo y el imaginario colectivos» (Baczko,
1991:69). Esta imaginación utópica estará presente no solo en el germen mismo de la Revolución Cubana, sino también en los intelectuales alineados.

Como sostiene Duanel Díaz Infante, fue un argentino, Ezequiel Martínez Estrada, quien llegó más lejos en la celebración de la Cuba revolucionaria como utopía (20I4:I22). En uno de sus ensayos, "El Nuevo Mundo, la isla de Utopía y la isla de Cuba» (1964), Martínez Estrada homologa la revelación que tuvo Tomás Moro sobre una sociedad cuyos integrantes eran libres, leales y virtuosos, no diferenciaban clases sociales y distribuían el trabajo equitativamente, con la política revolucionaria de Cuba. Incluso afirma que Moro se inspiró en la descripción geográfica de la isla caribeña realizada por Pedro Mártir de Anglería para cartografiar Jauja. Pienso que en la breve enumeración que da título al mencionado ensayo, en sus sinécdoques y desplazamientos, puede acaso verificarse la hipótesis de Baczko antes referida.

Varios ańos antes, Alejo Carpentier había prescindido de la «mirada turística» o europea para construir, ya en el siglo XX, una visión utópica de América desde un punto de vista auténticamente americano. Su mirada enfocaba la iluminación singular de una realidad maravillosa cuyo caudal de mitologías sui generis constituiría una usina de re- 
latos únicos, independizada de patrones europeos. Para Carpentier la historia de América toda no es sino una crónica de lo real maravilloso. ${ }^{4}$ Esta mirada utópica de Carpentier (como el título de Martínez Estrada), procede por sinécdoque, ya que luego busca a América en Cuba y a Cuba en sus raíces afroamericanas.

Rosalba Campra ha escrito que las ciudades también se fundan dentro de los libros. Los críticos suelen coincidir en que Carpentier (modelo de intelectual total) funda literariamente La Habana sobre todo en "La ciudad de las columnas", ensayo aparecido en Tientos y diferencias (1964) y luego reeditado como texto independiente para acompañar doce fotografías de Paolo Gasparini sobre motivos arquitectónicos habaneros. 5 Pero frente a esta visión, que celebraba la tradicional alegría caribeña en consonancia con un espacio urbano donde se efectuaría la utopía revolucionaria, algunos escritores de la etapa poscomunista (desde I99I hasta hoy) como los mencionados Antonio José Ponte y Pedro Juan Gutiérrez opondrán una literatura donde la ciudad de La Habana surgirá como concreción simbólica y material de una contrautopía, y cuyo referente temporal privilegiado es siempre el llamado »Período Especial en Tiempos de Paz» (eufemismo acuñado por el gobierno revolucionario para enmascarar la terrible crisis de los ańos '9o en la isla). Si aceptamos que la ciudad puede leerse como texto -habría entonces una "gramática» de la ciudad cuyo elemento organizador, en el caso de Carpentier, constante urbana que conforma un estilo propio a una ciudad aparentemente sin estilo (Carpentier, 1996:63), sería la columna - se trata de concebir, como sugiere Yolanda Izquierdo, «un objeto estético generado por condiciones económicas, sociales y culturales, susceptible de lectura: en él se manifiestan formas y estructuras mentales y sociales» (Izquierdo, 2002:19).

Desde esta perspectiva, las figuraciones literarias de la calle - lugar donde las políticas de control y su desobediencia se tensionan - instauran, desde Carpentier hasta Ponte y Gutiérrez, una evolución hacia la indeterminación de límites entre los espacios públicos y los privados. Cito un fragmento de "La ciudad de las columnas»:

\section{Ver prólogo a El reino de este mundo.}

5 Si hubo una ciudad a la que este escritor regresó una y otra vez, ésa fue la capital cubana. El libro El amor a la ciudad. La Habana de Alejo Carpentier, publicado por Alfaguara en 1996, reúne artículos, crónicas, un ensayo y una conferencia, escritos entre 1925 y 1973, que la incluyen como referente privilegiado. Asimismo, la urbe habanera también tiene una gran importancia en novelas como El acoso (1958), El siglo de las luces (1962) (especialmente al inicio) y La consagración de la primavera (1978). 
En todos los tiempos fue la calle cubana bulliciosa y parlera, con sus responsos de pregones, sus buhoneros entrometidos, sus dulceros anunciados por campanas mayores que el propio tablado de las pulpas, sus carros de frutas, empenachados de palmeras como procesión en Domingo de Ramos, sus vendedores de cuanta cosa pudieron hallar los hombres, todo en una atmósfera de sainete a la Ramón de la Cruz antes de que las mismas ciudades engendraran sus arquetipos criollos, tan activos ayer en los escenarios de bufos, como, más tarde, en la vasta imaginería — mitología - de mulatas barrocas en genio y figura, negras ocurrentes y comadres presumidas, pintiparadas, culiparadas, trabadas en regateos de lucimiento con el viandero de las cestas, el carbonero de carro entoldado a la manera goyesca, el heladero que no trae sorbetes de fresa el día en que le sobran los mangos, o aquel otro que eleva, como el Santísimo, un mástil erizado de caramelos verdes y rojos para cambiarlos por botellas. Y, por lo mismo que la calle cubana es parlera, indiscreta, fisgona, la casa cubana multiplicó los medios de aislarse, de defender, en lo posible, la intimidad de sus moradores. (I996:65)

En este pasaje, la sensorialidad puesta en juego por Carpentier conecta con la abun- dancia, el exceso, el espacio de la celebración. Así, es el artefacto lingüístico que diseña (acaso como expresión barroca del horror vacui y desde la fascinación encontrada en los relevamientos) el que articula la mirada utópica. Carpentier, alineado con la Revolución, pero capaz de transitar por lenguas y lenguajes diversos, puede pensarse como encarnación del modelo fáustico, es decir, como encarnación de un deseo propio del sujeto moderno orientado a poseer, controlar y saber todo. De allí que su escritura, con frecuencia, se oriente hacia el catálogo festivo, como en el fragmento citado. La extensa enumeración, por otra parte, aparece encabezada por un complemento verbal que proyecta la descripción no solo hacia el pasado sino también hacia el futuro.

Si Carpentier fundó su literatura como una catedral barroca erigida en la selva, escritores como Pedro Juan Gutiérrez o Antonio José Ponte preferirán dinamitar el paisaje de La Habana para pensarlo como zoológico, reserva natural o parque temático de un socialismo en extinción. Para un escritor como Gutiérrez, por ejemplo, el espacio de la calle servirá para trazar paisajes marcados por una estética vinculada al llamado realismo sucio ${ }^{6}$, donde los pintorescos vendedores de la

6 La categoría "realismo sucio" (más comercial que teórica) deriva del Dirty Realism norteamericano (representado por escritores como Henry Miller, Raymond Carver y Charles Bukowski). A grandes, rasgos, son narrativas centradas en el discurso de los marginados y caracterizadas por situaciones de excesiva violencia física, sexual y lingüística. En Cuba, los textos relacionados con esta tendencia escenifican tensiones dicotómicas como individuo/sociedad, ley/transgresión, utopía/contrautopía. 
ciudad de Carpentier se mixturan con sujetos individualistas que, muy lejos del Hombre Nuevo de Guevara, transforman su propio cuerpo en moneda de cambio:

Eran las siete de la tarde, pero el sol aún estaba alto y fuerte. Caminó despacio, llegó frente al Hotel Deauville y descansó un rato sentado en el muro. Había poca gente. De noche el lugar se cubre de jineteras y chulos, travestis, mariguaneros, gente de provincias que no se enteran de nada. Pajeros, vendedoras de maní, jineteros con ron y tabaco falsificado y coca verdadera, puticas recién importadas desde las provincias, músicos callejeros con guitarras y maracas, vendedoras de flores, triciclos con sus taxi-drivers multioficio, policías, aspirantes a emigrantes. Y algunas mujeres infelices, algunas viejas, algunos niños, los más pobres entre los pobres, que se dedican a pedir monedas incesantemente. (Gutiérrez, 2004:38)

Lejos de Carpentier, esta vertiente de la literatura del «Período Especial» compila historias de individuos sumergidos en la marginación y la decadencia para mostrar el lado B del proceso revolucionario. Frente al héroe capaz de morir para defender los ideales de la Revolución, cuyo epítome evidente es Guevara, surgen textos protagonizados por sujetos residuales, productos de los efectos secundarios del intento fallido de producir en serie al Hombre Nuevo. Por eso, en sintonía con la frase de Aznar citada en la apertura de este trabajo, numerosos escritores de la etapa postsoviética se referirán a la Cuba socialista empleando fórmulas como «isla burdel» (Chaviano, 1998:292), "teatro político" (Gutiérrez, 2007:34), "parque temático de la Guerra Fría» (Ponte, 2007:35), metaforizando el cruce entre ideología y espectáculo comercial.

Esta nueva estética emergente puede pensarse, por ejemplo, a través de la noción de ruina. Tanto en los textos de Ponte como en los de Gutiérrez, las ruinas proliferan. Su mirada sesgada enfoca siempre la faceta más sórdida de la ciudad de La Habana y perfila un submundo de regiones urbanas que parecen haber sido bombardeadas. Si para el turista la contemplación de las ruinas habaneras (en sentido amplio, el cuerpo de Fidel sería otra de ellas) causa asombro y hasta placer estético, para quienes las habitan son fuente de temor y sentimiento de provisionalidad. La Habana de estos escritores parece estar siempre al borde del derrumbe (no es ocioso recordar que esta palabra proviene del latín ruěre, que significa caer). Así, el sistema totalitario impuesto por la Revolución (desde las lecturas de Ponte y Gutiérrez) genera residuos que simbolizan la fugacidad del tiempo y también el fracaso. Pero a su vez la transformación simbólica derivada del abandono de los edificios de Centro Habana y La Habana Vieja deviene categoría estética. En la figura de la ruina 
se tensionan los pares horizontalidad/ verticalidad y orden/entropía, aunque también el pasado y el presente, por lo que puede observarse como palimpsesto en el sentido en que Rosalba Campra habla de "adensamiento del tiempo», es decir, un signo dual -la ruina es y no es al mismo tiempo- donde se superponen capas de significación vinculadas con la dimensión temporal.

En este sentido, la polisemia inherente a la noción de ruina admite considerarla, a un tiempo, atractivo turístico, refugio y trampa mortal para sus habitantes. Gutiérrez, por su lado, despliega un sistema de metáforas en el cual, para Esther Whitfield, los clichés (gente despreocupada dedicada a los placeres de la música, del baile, del ron y del sexo) remiten al hedonismo de la era prerrevolucionaria (Whitfield, 20Io:88) y las ruinas arquitectónicas de Centro Habana (municipio conformado por Cayo Hueso, Colón y el Barrio Chino) representan claras figuras de la decadencia de la utopía socialista cubana. De allí que el lenguaje metafórico derivado («ruindad», «ruina económica», «vida arruinada») se propague como marca de una estética singular.

Para Antonio José Ponte, además, las ruinas («accidentes en cámara lenta», dice Cocteau en Round the World Again in 80 Days) impugnan la distinción entre los espacios públicos y los privados, en tanto se caracterizan justamente por la simultaneidad o indistinción entre inte- rior y exterior (Ponte, 2007:168). Por eso Ponte, escritor que se autodefinió como «ruinólogo del siglo XXI», destaca el «envidiable carácter museístico» (Ponte, 2007:178) de la capital cubana. Una de sus hipótesis más sugestivas incluso atribuye a los dirigentes revolucionarios una intencionalidad en la "construcción» de ruinas. Señala Ponte en La fiesta vigilada:

La Habana actual es una creación de ese mismo estilo: de entre las posibilidades que se le abrieron en octubre de 1962, durante la crisis de los misiles, decidió convertirse en la ciudad que sufriera ataques, bombardeos, invasión. Es el escenario de una guerra no ocurrida nunca. (...) La proximidad estadounidense ha sido una feliz ocurrencia, recordada en cada una de las alocuciones públicas. La Habana, para un pensamiento de esta índole, es menos una capital viva que un paisaje de legitimación política, hecho a la medida de la verdadera ańoranza, escondida mal que bien en los discursos. Añoranza del ataque que John F. Kennedy no propició, ni ha propiciado ninguno de sus sucesores. (2007:204)

Más tarde, en el documental Habana - Arte nuevo de hacer ruinas (2006, Florian Borchmeyer), complementa esta hipótesis:

todo el discurso de Fidel Castro en este momento, y desde hace muchos años, desde el inicio, se basa en la invasión 
norteamericana. La ciudad de La Habana, manteniéndose en ruinas, corresponde exactamente con ese discurso. De algún modo, para legitimar el poder político, Fidel Castro ha dicho que estamos a punto siempre de estar invadidos por Estados Unidos. Para legitimar, arquitectónicamente, ese discurso político, la ciudad tiene el aspecto de haber sido ya bombardeada, $y$ de haber sido invadida.

Según la provocadora conjetura de Ponte, el fatalismo o determinismo causado por la visión y la vivencia de las ruinas, el convencimiento sobre la imposibilidad de revertir el proceso de abandono, sumerge a los ciudadanos en un estado de inmovilidad y estancamiento, que también es otra clave interpretativa fundamental en la poética de Gutiérrez. «Si tú no puedes cambiar tu casa, no puedes cambiar tu reino» es la fórmula que sintetiza la exégesis que Ponte hace de este aspecto de la realidad cubana. En estos paisajes abandonados, la condición espectacular de la figura de Guevara, la Revolución de los jóvenes barbudos, se complementa con este escenario donde las ruinas también devienen (acaso inesperadamente) productos de exportación turística. Así, los fragmentos citados de Carpentier, Gutiérrez y Ponte iluminan operatorias discursivas contrapuestas, aunque elocuentes en relación con un desplazamiento desde una escritura cele- bratoria de la ciudad hacia otra signada por el desencanto.

Ya Baczko (luego de hacer un detallado recorrido por la evolución e influencia de los discursos utópicos durante siglos) había concluido en Los imaginarios sociales, que desde los años setenta dejaba de estar en boga la exaltación de la utopía. En cambio, se la empezaba a considerar como negación del individuo en pos de un sistema racionalista y artificial: «La utopía no sería libertaria y subversiva; por el contrario, no es más que el enemigo mismo de la libertad, todavía más peligroso en la medida en que se disimula por medio de seductores encantos. La utopía sería la anticipación del universo totalitario" (I991:I05). Si bien, como es obvio, sería reductivo transponer sin matices este cambio de paradigma al caso cubano, resulta atractivo pensar los gestos narrativos de Gutiérrez y Ponte, en el contexto de la Revolución, como reacción a este giro planteado por Baczko vinculado a las nociones de utopía/totalitarismo. Para Baczko:

Más allá de la multiplicidad de utopias, solamente existiría un único y mismo proyecto utópico que, por su esencia misma, es totalitario. Geometría del orden social, la eterna utopía persigue a la fantasía, estrangula a la libertad, combate la marginalidad. La utopía, sistema cerrado y autárquico, es una máquina delirante que sirve para fabricar simetrías, para producir y reproducir lo 
mismo. El Estado utópico funciona como un gigantesco cuartel, y pide además que ese modo de vida sea aceptado con entusiasmo como si fuera el mejor. El individuo está subordinado, si no al Estado, por lo menos a lo colectivo, la igualdad mata a la libertad, la felicidad individual es sacrificada por la felicidad colectiva planificada por racionalistas aberrantes y demoníacos, locos de la perfección. ¿Cómo no reconocer en todo esto el universo totalitario? (IO5)

En esta línea de lectura, pienso entonces La Habana literaria en ruinas como un dispositivo ${ }^{7}$ contrautópico que excede la mera ilusión referencial para generar una estética que configura modos de habitar. Dicho de otro modo, si en la hipótesis de Ponte el gobierno revolucionario produce ruinas para legitimar su discurso y aletargar a la población, en Gutiérrez esas ruinas generan una estética de lo sucio y una subjetividad signada por el no-tiempo de los animales. Salvaje asalto a los sentidos del lector, Gutiérrez rechaza en su literatura toda apelación al entendimiento: prefiere que sus textos se huelan, se vean, se experimenten; pero siempre (en las antípodas de Carpentier) desde una retórica despojada. Antibarroca en lo lingüístico, pero capaz de crear el necesario efecto de escasez. A la crisis económica, su escritura opone una economía discursiva, desde la estructura morfosintáctica, pero ade- más desde la austeridad lexical: ningún lirismo, ninguna expresividad, ningún colorido ni adjetivación profusa. Por eso, en Pedro Juan Gutiérrez, el anclaje es en el inconsciente y en los sentidos que no se controlan, especialmente en el olfato (a diferencia del ojo, que sí se controla). Si hay abundancia (como había en el pasaje citado de Carpentier) ahora es, en todo caso, abundancia de lo desagradable. La operatoria es doble: la sinécdoque como tropo privilegiado proyecta lo particular en lo general, pero su duplicación intratextual enfatiza los efectos de lectura y dota de homogeneidad el universo ficcional de Gutiérrez.

Por otro lado, numerosas inflexiones de la literatura de los '9o desmontan la dicotomía ciudad-naturaleza desde fronteras móviles e inestables. Tradicionalmente, la ciudad recorta un espacio autónomo a la naturaleza indeterminada y caótica. En Ponte y Gutiérrez, sin embargo, el campo brota de modo azaroso para pervertir la función originaria de ciertos espacios urbanos. En estos textos, ninguna línea divisoria podría delimitar lo urbano de lo rural: dentro de su propio espacio la ciudad reconoce parcelas donde, por ejemplo, los puercos y pollos se reproducen contaminando azoteas y solares o donde un chivo vive temporalmente como un integrante más de la familia. Estas zonas textuales trazan efectos de resonancia, 
ecos de una (re)escritura atrapada (como los personajes, como el lector) en regiones invadidas por la escasez, los animales y la suciedad (sinécdoques de la crisis económica y sus consecuencias). Esta reduplicación intratextual de espacios, escenas y personajes promueve el énfasis discursivo, entendido como fenómeno expresivo, pero también connotativo y verosimilizante. Como afirma Max Gurian, los solares y los viejos edificios pueden pensarse desde una relación de contigüidad respecto del espacio público de la calle. Las viviendas tugurizadas (la expresión es de Ponte) se transforman en espacios comunitarios, de hacinamiento y reproducción descontrolada de animales y microbios.

No obstante, en Gutiérrez la ruina surge también como trampa. En este sentido, en el relato "Yo, claustrofóbico», el episodio autobiográfico del accidente en el ascensor configura una atmósfera (socia) (surrea)lista donde la ruina, signo connotado como organismo vivo, parece estar también sujeta a la muerte. El antiguo elevador «es como un viejo con arterioesclerosis: todo se le olvida y anda arriba y abajo, muy despacio, estremeciéndose y resoplando, como si ya no tuviera fuerzas para tanto trajín» (Gutiérrez, 2007:30). La comparación humaniza la mecánica del elevador, a la vez que lo convierte en un ser monstruoso e impredecible, que ataca con movimientos espontáneos para devorar o atrapar. Así, la ruina adquiere rasgos humanos y el hombre, su reverso, deviene ruina: «todo el brazo y la mano en carne viva, sangrando, y los nervios convertidos en un puré podrido de fango y mierda de perro. (...) Estuve encerrado dentro de mí, derrumbándome dentro de mí» (3I). Aquel espacio estilizado de Carpentier se interpone ahora como una fuerza extrańa, para mutilar al hombre o para determinar sus modos de habitar en zonas donde el desmoronamiento es siempre inminente. Lejos del ideal moderno del espacio ordenado, el horror de una ciudad caótica, sucia, y atravesada por la violencia, cartografía una suerte de angustia kafkiana evocada por la imagen repetida de la ciudad como prisión o (para ser riguroso) como jaula.

Pero para el ciudadano de La Habana, la contrautopía se materializa también desde la ya señalada degradación de la función originaria de los elementos que conforman el espacio habitado. En este

8 Este relato integra el volumen Trilogía sucia de La Habana. Un accidente en un antiguo ascensor, sumerge al protagonista en la claustrofobia. Tiempo después, conoce en un seminario de cine a la guionista brasileña Rita Cassia, con quien sostendrá una fugaz relación hasta que ella abandona la isla. Rita le promete no regresar: "ya me había dicho que le dolía mucho ver tanta miseria y tanto teatro político para disimularla" (34). 
sentido, Gurian (2009) observa que en la literatura de Gutiérrez las azoteas resultan también útiles como plataforma para suicidas y que «los grifos y las gárgolas, utilizadas como desagües en la arquitectura anglosajona, se ubican aquí frente al mar en un edificio que carece de agua corriente». Carpentier decía, en «La ciudad de las columnas", que con la columna, la reja, el guardavecinos, el guardacantón (a veces un motivo de adorno, en el remate de una ventana; un mascarón; una boca de gárgola en la esquina de un tejado) el estilo cubano se definía para la calle (1996:68). El contraste es evidente. Si en Carpentier entonces, la columna representaba la constante que conformaba el estilo propio de La Habana, en Gutiérrez incluso servirá de soporte para escenas de sexo exhibicionista: «Llegó hasta Muralla y se sentó bajo el arco de esa calle hacia la Avenida del Puerto. En la oscuridad. Tranquilo. Un poco más allá un negro y una negra templaban desaforadamente, de pie, recostados contra una columna, a seis metros de él» (2007:353).

Como se ve, Gutiérrez y Ponte asumen una posición en la batalla simbólica desatada por la Revolución Cubana, focalizando las regiones más afectadas por el abandono y la nada cotidiana. Gutiérrez lo hace siguiendo aquel postulado impresionista preconizado por Mallarmé: «Pintar no el objeto sino el efecto que produce». Su operatoria discursiva, entonces, se orientaría a reproducir en la lectura no tanto la ilusión de un referente (La Habana durante la crisis), sino sobre todo un efecto de obsolescencia del porvenir, de imposibilidad de progreso o emancipación del sujeto que lo habita. De este modo, el escritor nacido en Matanzas regresa literariamente a escenarios visitados por Carpentier para señalar su decadencia y articular una mirada que impugna toda dimensión utópica en el presente y el futuro de la isla.

En Antonio José Ponte, en cambio, la ruina (su efecto de superposición espacio-temporal) dispara las más variadas disquisiciones. Si para María Zambrano las ruinas son una tragedia sin autor, para Ponte el nuevo tiempo histórico introducido por la Revolución, frenético y transformador en un comienzo, produce después la museificación de La Habana. Deja, en primer lugar, la huella de una invasión jamás ocurrida. Luego propicia el usufructo turístico del centro urbano. Pero la ficción del ataque inexistente, además, genera novedosos modos de habitar una atmósfera espectacular, en tanto el escenario de un bombardeo sin bombardeo puede ser visitado por los turistas como si se tratara de un parque temático de la posguerra.

Frente al quiebre del dogmatismo ideológico, la lógica de intercambio comercial adquiere estatuto de pensamiento. Por eso el Hombre Nuevo de Guevara deviene hombre reificado, es decir, co- 
sificado y sujeto a las leyes de mercado. ${ }^{9}$ «McDisneyzación del turismo» (como escribió George Ritzer), «McGuevara’s» o "CheDonald's» (como cantó Kevin Johansen en una de sus canciones), Cuba se convierte hacia fines del siglo pasado una de las mecas favoritas del turismo ideológico. La Revolución reificada renace como espectáculo multitemporal, en tanto, como afirma Duanel Díaz Infante, la insólita confluencia de lo antiguo con lo moderno, lo prerrevolucionario y lo revolucionario, lo capitalista y lo socialista (no solo en los motivos arquitectónicos sino también en los interiores de las viviendas) provoca un efecto estético (2014:207). Este eclecticismo produciría paradójicamente un retorno del «estilo sin estilo» del que hablaba Carpentier en «La ciudad de las columnas», vinculado a aquel real maravilloso que caracterizaría el continente americano para dicho escritor. Cabe preguntarse entonces de qué modo La Habana textual, La Habana hecha de palabras (reinvención, a su vez, de la ciudad geográfica que está fuera de los textos), se constituye en centro generador de un imaginario social donde la utopía dominante del siglo veinte resulta irreversiblemente penetrada por la sociedad de consumo. ¿Serán las ruinas y este hombre reificados el escenario y los actores (las atracciones) de un parque temático de la Revolución...?

Referencias bibliográficas

- BACZKO, B. (1991). Los imaginarios sociales (trad.: Pablo Betesh). Buenos Aires: Nueva Visión.

- BENJAMIN, W. (1989). La obra de arte en la época de su reproductibilidad técnica. Discursos interrumpidos 1 (pról., trad. y notas: Jesús Aguirre). Buenos Aires: Aguilar, Altea, Taurus, Alfaguara.

- CAMPRA, R. (1994). La ciudad en el discurso literario". SyC, (5). Buenos Aires: Facultad de Filosofía y Letras.

- CARPENTIER, A. (1973). El reino de este mundo. México: Compañía general de ediciones.

- _ (1996). La ciudad de las columnas. El amor a la ciudad.

La Habana de Alejo Carpentier. Madrid: Alfaguara. 
- CHAVIANO, D. (1998). El hombre, la hembra y el hambre. Barcelona: Planeta.

- DE LA NUEZ, I. (2013). El comunista manifiesto. Barcelona: Galaxia Gutenberg.

- DÍAZ INFANTE, D. (2012). La Revolución es el espectáculo". Diario de Cuba [en línea]. Consultado el 1 de abril de 2017 en: http://www.diariodecuba.com/cultura/1344672447_694.html -__ (2014). La revolución congelada. Dialécticas del castrismo. Madrid: Verbum.

- GURIAN, M. (2009). Animales tropicales: bestiarios poshistóricos en la literatura latinoamericana. ACTAS del VII Congreso Internacional Orbis Tertius de Teoría y Crítica Literaria [en línea]. Consultado el 1 de abril de 2017 en: http://viicitclot.fahce. unlp.edu.ar/actas-del-vii-congreso-internacional-orbis-tertius-1/ ponencias/Gurian.pdf

- GutiÉRREZ, P. J. (2004). El Rey de La Habana. Barcelona: Anagrama.

- _- (2006). Animal tropical. Barcelona: Anagrama.

- - (2007). Trilogía sucia de La Habana. Barcelona: Anagrama.

- IZQUIERDO, Y. (2002). Acoso y ocaso de una ciudad: La Habana de Alejo Carpentier y Guillermo Cabrera Infante. San Juan: Isla Negra Editores.

- JITRIK, N. (1994). Voces de ciudad. SyC, (5). Buenos Aires: Facultad de Filosofía y Letras.

- LUKACS, G. (1970). Reificación y consciencia del proletariado. Historia y conciencia de clase. La Habana: Editorial de ciencias sociales.

- MESA-LAGO, C. (2012). Cuba en la era de Raúl Castro. Madrid: Colibrí.

- ORTEGA, J. (1990). El discurso de la abundancia. Caracas: Monte Ávila.

- PONTE, A. J. (2005). Un arte de hacer ruinas y otros cuentos. México: Fondo de Cultura Económica.

- __ (2007). La fiesta vigilada. Barcelona: Anagrama.

- WHITFIELD, E. (2010). Mercados en los márgenes: el atractivo de Centro Habana. Katatay, VI(8, noviembre), 86-106. La Plata. 